\title{
Self-reported psychosis-like experiences in patients with mood disorders
}

\section{Baryshnikov, I.}

2018-06

Baryshnikov , I , Suvisaari , J , Aaltonen , K , Koivisto , M , Melartin , T , Näätänen , P ,

Suominen , K , Karpov , B , Heikkinen, M , Oksanen , J , Paunio , T , Joffe , G \& Isometsä , E 2018 , ' Self-reported psychosis-like experiences in patients with mood disorders ', European Psychiatry , vol. 51 , pp. 90-97 . https://doi.org/10.1016/j.eurpsy.2016.07.005

http://hdl.handle.net/10138/302456

https://doi.org/10.1016/j.eurpsy.2016.07.005

publishedVersion

Downloaded from Helda, University of Helsinki institutional repository.

This is an electronic reprint of the original article.

This reprint may differ from the original in pagination and typographic detail.

Please cite the original version. 


\title{
Original article
}

\section{Self-reported psychosis-like experiences in patients with mood disorders}

\author{
I. Baryshnikov ${ }^{\text {a }}$, J. Suvisaari ${ }^{\text {a,c }}$, K. Aaltonen ${ }^{\text {a,b }}{ }^{\text {, M. Koivisto }}{ }^{\text {a }}$, T. Melartin ${ }^{\text {a }}$, P. Näätänen ${ }^{\text {a }}$, \\ K. Suominen $^{\text {b }}$, B. Karpov ${ }^{\text {a }}$, M. Heikkinen ${ }^{\text {a }}$, J. Oksanen ${ }^{\text {b }}$, T. Paunio ${ }^{\text {a }}$, G. Joffe ${ }^{\text {a }}$, E. Isometsä ${ }^{\text {a,c,* }}$ \\ ${ }^{a}$ Department of Psychiatry, University of Helsinki and Helsinki University Hospital, P.O. Box 22 (Välskärinkatu 12 A), 00014 Helsinki, Finland \\ ${ }^{\mathrm{b}}$ Department of Mental Health and Substance Abuse, Social Services and Health Care, Helsinki, Finland \\ ${ }^{\mathrm{c}}$ National Institute for Health and Welfare, Mental Health Unit, 00271 Helsinki, Finland
}

\section{A R T I C L E I N F O}

\section{Article history:}

Received 6 June 2016

Received in revised form 12 July 2016

Accepted 12 July 2016

Available online 3 February 2017

\section{Keywords:}

Psychosis-like symptoms

Mood disorder patients

Borderline personality disorder

\begin{abstract}
A B S T R A C T
Background: Self-reported psychosis-like experiences (PEs) may be common in patients with mood disorders, but their clinical correlates are not well known. We investigated their prevalence and relationships with self-reported symptoms of depression, mania, anxiety, borderline (BPD) and schizotypal (SPD) personality disorders among psychiatric patients with mood disorders.

Methods: The Community Assessment of Psychic Experiences (CAPE-42), Mood Disorder Questionnaire (MDQ), McLean Screening Instrument (MSI), The Beck Depressive Inventory (BDI), Overall Anxiety Severity and Impairment Scale (OASIS) and Schizotypal Personality Questionnaire-Brief form (SPQ-B) were filled in by patients with mood disorders $(n=282)$ from specialized care. Correlation coefficients between total scores and individual items of CAPE-42 and BDI, SPQ-B, MSI and MDQ were estimated. Hierarchical multivariate regression analysis was conducted to examine factors influencing the frequency of self-reported PE.

Results: PEs are common in patients with mood disorders. The "frequency of positive symptoms" score of CAPE-42 correlated strongly with total score of SPQ-B (rho $=0.63 ; P<0.001$ ) and moderately with total scores of BDI, MDQ, OASIS and MSI (rho varied from 0.37 to $0.56 ; P<0.001$ ). Individual items of CAPE-42 correlated moderately with specific items of BDI, MDQ, SPQ-B and MSI ( $r_{\varphi}$ varied from 0.2 to 0.5 ; $P<0.001)$. Symptoms of anxiety, mania or hypomania and BPD were significant predictors of the "frequency of positive symptoms" score of CAPE-42.

Conclusions: Several, state- and trait-related factors may underlie self-reported PEs among mood disorder patients. These include cognitive-perceptual distortions of SPD; distrustfulness, identity disturbance, dissociative and affective symptoms of BPD; and cognitive biases related to depressive or manic symptoms.
\end{abstract}

(c) 2016 Elsevier Masson SAS. All rights reserved.

\section{Introduction}

Self-reported psychosis-like experiences (PEs) resemble positive psychotic symptoms and are experienced also by individuals without psychotic illness [1,2]. Numerous epidemiological studies have indicated that self-reported PEs are common in both the general population [3-6] and patients with different mental

\footnotetext{
* Corresponding author. Department of Psychiatry, P.O. Box 22 (Välskärinkatu 12 A), 00014 Helsinki, Finland. Tel.: +358 9 4711; fax: +358 947163735.

E-mail address: erkki.isometsa@hus.fi (E. Isometsä).
}

disorders [7-10]. Individuals with depression and anxiety are known to more likely report PEs than healthy individuals $[11,12]$. Moreover, some studies have indicated that the severity of mental disorder correlates with frequency and persistency of self-reported PEs [13,14]. PEs have been associated with psychological distress $[15,16]$ and higher risk for suicidal thoughts and behaviour $[17,18]$.

Many studies indicate that self-reported subthreshold PEs are more prevalent than symptoms exceeding psychotic threshold $[3,19,20]$. The noticeable overlap of psychotic and mood disorders in genetic [21,22], neurobiological $[23,24]$ and environmental risk factors [25] reflects a phenomenological overlap of psychotic and 
mood disorders on both clinical and subclinical levels [26]. However, frank psychotic symptoms are also common in mood disorders, and differences in their prevalence between diagnostic subgroups have been described. For instance, lifetime psychotic symptoms were reported by half of patients with bipolar I disorder (BD-1), twice as common than those with bipolar II disorder (BD-2), the latter having had psychotic symptoms only when depressed [27]. For definition of unipolar depression (UD) with psychotic features, there is a disagreement between the diagnostic classifications of the International Classification of Diseases 10th Revision (ICD-10) [28] and the Diagnostic and Statistical Manual of Mental Disorders Fifth Edition (DSM-5) [29], regarding relationship to severity of depressive symptoms. The majority of studies indicate that psychotic symptoms in UD tend to emerge in the more severe depressive episodes [30-32], but some studies revealed that depression with psychotic features was not necessarily associated with severity of depressive symptoms [33-36]. However, psychotic symptoms in UD were associated with an increased risk for relapse [33], greater morbidity and residual impairment [37] and worse outcome of psychotherapy [38].

Both PEs and dissociative symptoms are also among the core features of some personality disorders, including borderline (BPD) and schizotypal (SPD) personality disorders. Comorbidity of mood disorders with personality disorders is high $[39,40]$. Patients with UD appear more likely to have cluster A personality disorders and patients with BD cluster B personality disorders [41]. A higher occurrence of self-reported PEs and dissociative symptoms in individuals with personality disorders was associated with higher distress and worse treatment response [42-44]. Moreover, patients with self-reported features of BPD or SPD are more likely to develop a psychotic disorder $[45,46]$.

Detecting of frank psychotic symptoms in patients with mood disorders is important because of treatment implications [4749]. As mentioned before, subthreshold PEs in patients with mood disorders may have negative prognostic effect on their course and therefore detecting of PEs is also important, although their treatment implications are poorly understood. However, their clinical correlates are not well known.

The Community Assessment of Psychic Experiences (CAPE-42) has been shown to be a useful self-reported measure of positive, negative and depressive symptoms with good reliability and validity [50]. We investigated self-reported PEs measured by CAPE42 in patients with UD and BD to determine the relationships between self-reported PEs and self-reported symptoms of depression, mania or hypomania, anxiety, BPD and SPD. We hypothesized that partial overlap of PEs and mood disorders symptoms can be observed at the level of self-reported features and the symptoms are associated with: (a) the severity of mood disorders and, (b) coexistent features of BPD and SPD. Therefore, we investigated correlations of the CAPE- 42 positive scale with self-reported scales of anxiety, mood disorders, SPD and BPD on both total scores and item level and examined factors influencing the prevalence of selfreported psychotic symptoms in patients with mood disorder.

\section{Methods}

The Helsinki University Psychiatric Consortium (HUPC) study design, setting and patient sampling processes are presented in detail elsewhere [51,52], but are briefly outlined below.

\subsection{Setting}

The study was conducted in 10 community mental health centres, three psychiatric inpatient units and one day-hospital offering specialized secondary public mental health services in the metropolitan area of Helsinki between 12.1.2011 and
20.12.2012. The catchment area (mean population 1139222 in 2012) encompasses the Helsinki metropolitan area, including the cities of Helsinki, Espoo, Vantaa, Kauniainen, Kerava, and Kirkkonummi where free-of-charge psychiatric secondary care services are provided to the residents of the area.

\subsection{Sampling}

Inclusion criteria were patients' age of over 18 years and provision of informed consent. Patients with mental retardation, neurodegenerative disorders and insufficient Finnish language skills were excluded. Stratified patient sampling selection was performed by identifying all patients within a certain day or week in a unit or by randomly drawing eligible patients from patient lists. Patients treated for psychotic disorders, neuropsychiatric disorders, anxiety disorders, eating disorders, BPD, or substance use disorders as lifetime principal diagnosis were excluded from this study. Of the 902 eligible patients with mood, neurotic or personality disorders, 372 refused to participate and 217 were lost for other reasons. Thirty-one patients with other lifetime diagnoses were excluded.

\subsection{Clinical diagnoses}

The validity of the clinical diagnoses assigned by the attending physicians was critically evaluated by the authors by re-examining all available information from patient records. The validated clinical diagnoses were based on the ICD-10. Lifetime principal diagnosis was assigned. We subtyped patients with BD into type I (BD-1), type II (BD-2) and not otherwise specified (BD-NOS) according to the DSM-IV.

\subsection{Description of patients}

Altogether 282 patients participated in the study. Their mean age was $42.2 \pm 13.1$ years, and 209 (74.1\%) were female. Epidemiological characteristics of patients are presented in Table 1 . There were 183 patients with UD (F32-F33) and 99 patients with BD (F31). Among patients with BD, 36 (36.3\%) had BD-1, 55 (55.5\%) BD-2 and 8 (8\%) BD-NOS. Patients with BD-NOS and BD-2 were allocated to the same group. Nineteen patients with BD (20\%) were hospitalized due to psychotic mania or psychotic depression (3 patients with BD-2 and 16 with BD-1). Among patients with UD, 14 (8\%) had psychotic depression as a lifetime diagnosis.

\subsection{Community Assessment of Psychic Experiences (CAPE-42)}

The CAPE-42 is a self-reported questionnaire that measures lifetime psychotic experiences by using 42 items. The items measure symptoms in three main domains:

- Positive Symptoms (20 items);

- Negative Symptoms (14 items);

- Depression Symptoms (8 items).

Each item is rated at a 4-point Likert scale from 1 to 4 for both symptom frequency and the degree of distress experienced due to the symptom. Cronbach's alpha for CAPE-42 total score was 0.854 . According to previous studies of the factorial structure of positive symptoms [53] we grouped items into 5 groups-grandiosity, paranoia, magical thinking, delusions and hallucinations.

\subsection{McLean Screening Instrument (MSI)}

The MSI is a ten-item questionnaire designed according to DSM-IV diagnostic criteria to screen for BPD [54]. It has been 
Table 1

Sociodemographic characteristics of patients with mood disorders $(n=282)$.

\begin{tabular}{|c|c|c|c|c|c|c|}
\hline & \multicolumn{2}{|l|}{ BD } & \multicolumn{2}{|l|}{ MDD } & \multicolumn{2}{|l|}{ Total } \\
\hline & $n$ & $\%$ & $n$ & $\%$ & $n$ & $\%$ \\
\hline Number & 99 & 35 & 183 & 65 & 282 & 100 \\
\hline Age $($ mean $\pm S D)$ & $43.7 \pm 12.7$ & & $41.4 \pm 13.3$ & & $42.3 \pm 13$ & \\
\hline Sex (male) & 36 & 36.3 & 42 & 22.9 & 78 & 27.7 \\
\hline \multicolumn{7}{|l|}{ Marital status } \\
\hline Married & 20 & 20.2 & 39 & 21.3 & 59 & 21 \\
\hline Cohabiting & 17 & 17.2 & 29 & 15.8 & 46 & 16.3 \\
\hline Unmarried & 32 & 32.2 & 75 & 41 & 107 & 38.2 \\
\hline Divorced & 29 & 29.3 & 35 & 19.1 & 64 & 22.7 \\
\hline Widowed & 1 & 1 & 3 & 1.7 & 4 & 1.4 \\
\hline \multicolumn{7}{|l|}{ Work status } \\
\hline Disability pension due to mental disorder & 37 & 37.4 & 23 & 12.5 & 60 & 21.2 \\
\hline Unemployed & 10 & 10 & 18 & 9.8 & 28 & 9.9 \\
\hline Sick leave & 22 & 22.2 & 64 & 35 & 86 & 30.5 \\
\hline Disability pension for other illness & 1 & 1 & 8 & 4.4 & 9 & 3.2 \\
\hline Student & 7 & 7.1 & 24 & 13.1 & 31 & 10.9 \\
\hline Employed & 20 & 20.2 & 30 & 16.4 & 50 & 17.7 \\
\hline Not employed for other reasons & 2 & 2.2 & 14 & 7.7 & 16 & 5.7 \\
\hline
\end{tabular}

BD: Bipolar Disorder; MDD: Major Depressive Disorder.

translated into Finnish and validated in Finland [55]. Each item requires a "yes/no" response. Each positive item indicates the presence of BPD symptoms. The Kuder-Richardson 20 (KR-20) coefficient for MSI was 0.747 .

\subsection{Beck Depression Inventory (BDI)}

BDI is a self-report instrument designed to assess and detect the severity of current depressive symptoms (during the last week) in clinical and community settings [56]. It contains 21 descriptive statements regarding depressive symptoms frequently reported by individuals diagnosed with depression. Each of the items contains a 4-point severity-rating scale. Cronbach's alpha for BDI total score was 0.919 .

\subsection{Overall Anxiety Severity and Impairment Scale (OASIS)}

OASIS is a brief, 5-item self-report questionnaire to assess frequency, severity and impairment associated with anxiety [57]. The questionnaire includes five questions regarding the frequency and severity of anxiety symptoms as well as anxietyrelated avoidance behaviour and decreased functioning at home/ work/school and in social life. Responses range from zero to four. Cronbach's alpha for OASIS in the total sample was 0.80 .

\subsection{Schizotypal Personality Questionnaire-Brief form (SPQ-B)}

The SPQ-B is a 22-item self-report instrument derived from the 74-item SPQ questionnaire designed according to DSM-III-R diagnostic criteria for SPD [58]. Each positive item indicates the presence of SPD symptoms. Items were created to measure three dimensions of SPD: 8 items for cognitive-perceptual, 8 items for interpersonal and 6 items for disorganization. KR-20 separately was 0.651 for cognitive-perceptual, 0.807 for interpersonal and 0.737 for disorganized dimension.

\subsection{Mood Disorder Questionnaire (MDQ)}

The MDQ is a brief self-report instrument for screening lifetime symptoms or behaviours related to a manic or hypomanic syndrome [59], and it has been translated into Finnish [60]. In the correlation analysis only the first question's responses were used; Cronbach's alpha for them was 0.890, indicating excellent internal consistency.

\subsection{Statistical analysis}

The independent-samples t-test was conducted to compare differences between two continuous variables. The differences between three or more continuous variables were explored with ANOVA-test. For variables that met the assumption of homogeneity Tukey's honestly significant difference (Tukey's HSD) was used, otherwise we used the Games-Howell test in post hoc analysis. The correlation analysis was conducted between scales' total scores, their factors and items. Spearman's correlation coefficient was estimated between continuous variables. The phi-coefficient was calculated for binary variables and the point-biserial coefficient for dichotomous and continuous variables. To protect against Type I error in correlation analyses, Bonferroni corrections were conducted dividing the original $\alpha$-value by the number of analyses on the dependent variable. A correlation from 0.6 to 0.79 was regarded as "strong", from 0.40 to 0.59 as "moderate", from 0.20 to 0.39 as "weak" and less than 0.2 as "very weak" [61]. In hierarchical multivariate regression (HMR) analysis with dependent variables total scores of frequency of positive symptoms, the following predictors were used: age, sex, BDI, MDQ MSI and OASIS. SPQ-B was not included in the regression analysis to avoid collinearity bias. The analyses were performed by using SPSS version 22.0 [62].

\section{Results}

\subsection{Total scores of self-reported scales}

Overall, 273 patients (96.8\%) with mood disorder have reported experienced PEs "sometimes", "often" or "always". No differences were present between means of "frequency of positive symptoms" of patients with and without psychotic depression $(P=0.4)$. Likewise, no differences emerged between means of "frequency of positive symptoms" of BP patients with a history of psychotic episodes and those without psychotic episodes $(P=0.12)$. Differences in means of CAPE-42 "frequency of positive symptoms" between patients with BD-1, BD-2 and UD were not detected. Means of total scores of questionnaires are presented in Table 2.

\subsection{Frequencies of positive dimension's items of CAPE-42}

Frequencies of positive dimension's items and their means are shown in Table 3. Means of the item "external control" were higher in patients with BD-1 $(P<0.001)$. 
Table 2

Mean scores of self-report scales (MSI, BDI, SPQ-B, MDQ and OASIS) in patients with mood disorder $(n=282)$.

\begin{tabular}{|c|c|c|c|c|}
\hline Scale & $\begin{array}{l}\text { BD-1 } \\
\text { Mean (SD) } \\
n=36\end{array}$ & $\begin{array}{l}\text { BD-2 } \\
\text { Mean (SD) } \\
n=63\end{array}$ & $\begin{array}{l}\text { UD } \\
\text { Mean (SD) } \\
n=183\end{array}$ & $P^{\mathrm{a}}$ \\
\hline McLean Screening Instrument & $5.1(2.6)$ & $6.4(2.4)$ & $5.4(2.7)$ & $0.013^{\mathrm{b}}$ \\
\hline Beck Depression Inventory ${ }^{\mathrm{f}}$ & $17.5(9.7)$ & $24.8(11.8)$ & $27.5(12.4)$ & $0.001^{\mathrm{c}}$ \\
\hline Schizotypal Personality Questionnaire-Brief ${ }^{f}$ & $7.7(5.2)$ & $10.1(5.5)$ & $9.6(5.2)$ & 0.474 \\
\hline Mood Disorder Questionnaire ${ }^{g}$ & $10.4(2.9)$ & $9.9(3.2)$ & $5(3.7)$ & $0.0001^{\mathrm{d}}$ \\
\hline Overall Anxiety Severity and Impairment Scale ${ }^{\mathrm{h}}$ & $9.5(4.9)$ & $11.5(3.9)$ & $11(4.8)$ & 0.244 \\
\hline Frequency of positive symptoms ${ }^{\mathrm{i}}$ & $28.6(7.8)$ & $29.6(8.2)$ & $28.2(6.3)$ & 0.401 \\
\hline Distress of positive symptoms ${ }^{\mathrm{j}}$ & $13.4(10.9)$ & $17.3(14.5)$ & $13(10)$ & 0.206 \\
\hline Frequency of negative symptoms $\mathrm{s}^{\mathrm{k}}$ & $30.7(8.1)$ & $32.9(6.3)$ & $34.3(8.1)$ & $0.050^{\mathrm{e}}$ \\
\hline Distress of negative symptoms ${ }^{1}$ & $29.6(12.1)$ & $31.4(8.5)$ & $32.1(10.6)$ & 0.542 \\
\hline Frequency of depressive symptoms ${ }^{\mathrm{m}}$ & $18.0(4.4)$ & $20.0(4.5)$ & $20.8(4.8)$ & $0.033^{\mathrm{e}}$ \\
\hline Distress of depressive symptoms ${ }^{\mathrm{n}}$ & $18.1(6.9)$ & $19.6(5.7)$ & $20.8(6.6)$ & 0.142 \\
\hline
\end{tabular}

a $P$ by ANOVA.

b The mean MSI is higher in patients with BD-2 than BD1 $(P<0.005$ in post hoc by Turkey's HSD).

c The mean of BDI item scores is higher in patients with UD than BD- $1(P<0.05$ in post hoc by Turkey's HSD).

d The mean of MDQ is higher in patients with BD-1 than UD $(P<0.005$ in Post Hoc by Games-Howell).

e The means are higher in patients with UD than BDI- $1(P<0.005$ in post hoc by Games-Howell).

f Data missing for $0.3 \%$ of patients.

$g$ Data missing for $0.7 \%$ of patients.

h Data missing for $0.7 \%$ of patients.

i Data missing for $12.5 \%$ of patients.

j Data missing for $27.2 \%$ of patients.

${ }^{\mathrm{k}}$ Data missing for $7 \%$ of patients.

${ }^{1}$ Data missing for $21.6 \%$ of patients.

$\mathrm{m}$ Data missing for $4.5 \%$ of patients.

n Data missing for $15.7 \%$ of patients.

\subsection{Correlation analysis of total scores of self-reported scales}

Correlations between total scores of all questionnaires are given in Table 4. The CAPE-42 dimension "frequency of positive symptoms" correlated strongly with total scores of SPQ-B and moderately with MSI, OASIS, BDI and MDQ $(P<0.01)$. The CAPE-42 item group "paranoia" correlated strongly with total scores of MDQ, OASIS, SPQ-B and MSI $(P<0.001)$ and moderately with scores of BDI $(P<0.001)$. The item group "grandiosity" correlated moderately with the MDQ score $(P<0.001)$. The item' group "magical thinking" correlated moderately with SPQ-B scores $(P<0.001)$. "Delusions" correlated moderately with all questionnaires' scores. The group "hallucinations" correlated moderately with MSI and SPQ-B scores $(P<0.001)$.

\subsection{Item-by-item correlations of positive dimension items of CAPE-42 with}

\subsection{1. $M S I$}

Items of MSI "dissociative symptoms", "identity disturbance", "feeling of emptiness", "distrustfulness", "increased anger" and "mood instability" correlated moderately with specific CAPE-42 positive dimension items $\left(r_{p b}\right.$ varied from 0.2 to $\left.0.4 ; P<0.001\right)$ (see Supplementary Table 1$)$.

\subsection{2. $B D I$}

CAPE-42 items "being persecuted", "people look at you oddly because of appearance", "hints about you or things with double meaning" correlated moderately with the majority of BDI items $(P<0.001)$. BDI items "punishment feelings", "irritability", "worthlessness" and "self-criticalness" correlated moderately or weakly with CAPE-42 items (rho varied between 0.2 and 0.5 ; $P<0.001$ ) (see Supplementary Table 2).

\subsection{3. $M D Q$}

CAPE-42 items "being special or unusual person", "destined to be very important" and "being persecuted" correlated moderately or weakly with the majority of MDQ items $\left(\mathrm{r}_{\mathrm{pb}}\right.$ varied between 0.2 and $0.3 ; P<0.005$ ) (see Supplementary Table 3).

\subsubsection{OASIS}

CAPE-42 items "hints about you or things with double meaning", "being persecuted", "conspiracy against you" and "people look at you oddly because of appearance", among others, correlated moderately with all items of OASIS (rho varied from 0.2 to $0.4 P<0.01$ ) (see Supplementary Table 4 ).

\subsection{5. $S P Q-B$}

The majority of SPQ-B items correlated moderately with items of CAPE-42 $\left(r_{\mathrm{pb}}\right.$ varied between 0.2 to $\left.0.5 ; P<0.01\right)$ (see Supplement Table 5).

\subsection{Hierarchical multiple regression predicting the frequency of positive symptoms}

In collinearity diagnostics, the variance inflation factor was not higher than 2.0 for all predictors. The full model of age, sex, BDI, MDQ OASIS and MSI in predicting the frequency of positive symptoms was statistically significant $(\mathrm{R} 2=.352, \mathrm{~F}(4,240)=21.7$, $P<0.001$; adjusted $R 2=0.336)$. In the model 1 with predictors Age and Sex $(\mathrm{R} 2=.062, \mathrm{~F}(2,244)=8.0, P<0.001$; adjusted $\mathrm{R} 2=0.05)$ variable Age had a significant weight $(\beta=0.05)$. The addition of OASIS, BDI, MDQ and MSI to the prediction of the frequency of positive symptoms (Model 2) led to a significant increase in R2 of 0.290 with significant weight for age, OASIS, MSI and MDQ ( $\beta=-0.113 ; 0.161 ; 0.326 ; 0.139$, respectively) (Table 5 ).

\section{Discussion}

We found self-reported PEs to be prevalent among patients with mood disorders treated in specialized psychiatric settings. We demonstrated strong correlations between CAPE-42-measured lifetime self-reported PEs and features of borderline (BPD) and schizotypal (SPD) personality disorder, and a moderate correlation of lifetime self-reported PEs with current self-reported symptoms of anxiety, depressive symptoms and hypomania or mania.

To our knowledge, this is the first study examining selfreported PEs and their correlations with self-reported symptoms of BPD, SPD, depression, anxiety, mania or hypomania in mood 
Table 3

Frequencies of CAPE-42 positive dimension's items and their means in patients with mood disorders $(n=282)$.

\begin{tabular}{|c|c|c|c|c|c|c|c|c|c|c|c|c|c|c|c|c|}
\hline \multirow[t]{2}{*}{$\begin{array}{l}\text { CAPE- } 42 \\
\text { positive dimension's items }\end{array}$} & \multicolumn{4}{|l|}{$\begin{array}{l}\text { BD-1 } \\
n(\%) \\
n=36\end{array}$} & \multicolumn{4}{|l|}{$\begin{array}{l}\text { BD-2 } \\
n(\%) \\
n=63\end{array}$} & \multicolumn{4}{|l|}{$\begin{array}{l}\text { UD } \\
n(\%) \\
n=183\end{array}$} & \multicolumn{4}{|c|}{ Means (SD) } \\
\hline & Never & Sometimes & Often & Always & Never & Sometimes & Often & Always & Never & Sometimes & Often & Always & BDI-1 & BD-2 & UD & $P^{\mathrm{a}}$ \\
\hline $\begin{array}{l}\text { Hints about you or things with } \\
\text { double meaning }\end{array}$ & $16(44)$ & $14(39)$ & $6(17)$ & $0(0)$ & $17(27)$ & $28(46)$ & $8(13)$ & $9(15)$ & $49(27)$ & $81(44)$ & $41(22)$ & $14(8)$ & $1.9(0.9)$ & $2.0(0.9)$ & $2.1(0.9)$ & 0.48 \\
\hline $\begin{array}{l}\text { Things in magazines written } \\
\text { especially for you }\end{array}$ & $30(86)$ & $5(14)$ & $0(0)$ & $0(0)$ & $54(86)$ & $6(10)$ & $3(5)$ & $0(0)$ & $163(89)$ & $18(10)$ & $1(0.5)$ & $1(0.5)$ & $1.2(0.5)$ & $1.1(0.4)$ & $1.1(0.4)$ & 0.49 \\
\hline $\begin{array}{l}\text { Some people are not what they } \\
\text { seem to be }\end{array}$ & $16(44)$ & $15(42)$ & $3(8)$ & $2(6)$ & $23(37)$ & $28(44)$ & $11(18)$ & $1(2)$ & $74(40)$ & $78(42)$ & $26(14)$ & $6(3)$ & $1.8(0.9)$ & $1.8(0.7)$ & $1.8(0.8)$ & 0.99 \\
\hline $\begin{array}{l}\text { You are being persecuted in } \\
\text { some way }\end{array}$ & $23(64)$ & $9(25)$ & $3(8)$ & $1(3)$ & $40(65)$ & $14(23)$ & $5(8)$ & $3(5)$ & $117(65)$ & $48(27)$ & $15(8)$ & $1(0.5)$ & $1.6(0.9)$ & $1.5(0.8)$ & $1.4(0.7)$ & 0.50 \\
\hline There is conspiracy against you & $22(61)$ & $11(31)$ & $1(3)$ & $2(6)$ & $34(54)$ & $22(35)$ & $3(5)$ & $4(6)$ & $98(53)$ & $63(34)$ & $20(11)$ & $2(2)$ & $1.7(0.9)$ & $1.5(0.7)$ & $1.6(0.7)$ & 0.61 \\
\hline $\begin{array}{l}\text { You are destined to be someone } \\
\text { very important }\end{array}$ & $20(57)$ & $10(29)$ & $5(14)$ & $0(0)$ & $41(66)$ & $19(31)$ & $1(2)$ & $1(2)$ & $140(75)$ & $35(20)$ & $10(5)$ & $1(0.5)$ & $1.5(0.7)$ & $1.4(0.6)$ & $1.3(0.6)$ & 0.16 \\
\hline $\begin{array}{l}\text { You are very special or unusual } \\
\text { person }\end{array}$ & $8(22)$ & $16(44)$ & $10(28)$ & $2(6)$ & $14(22)$ & $30(48)$ & $15(24)$ & $4(6)$ & $68(37)$ & $65(35)$ & $35(19)$ & $16(9)$ & $2.2(0.8)$ & $2.1(0.9)$ & $2.0(1.0)$ & 0.34 \\
\hline $\begin{array}{l}\text { People can communicate } \\
\text { telepathically }\end{array}$ & $24(69)$ & $6(17)$ & $2(16)$ & $3(9)$ & $33(52)$ & $21(33)$ & $6(10)$ & $3(5)$ & $108(58)$ & $64(34)$ & $12(6)$ & $3(2)$ & $1.6(1.0)$ & $1.6(0.8)$ & $1.5(0.7)$ & 0.60 \\
\hline $\begin{array}{l}\text { Electrical devices can influence } \\
\text { the way you think }\end{array}$ & $32(89)$ & $3(8)$ & $1(3)$ & $0(0)$ & $60(95)$ & $2(3)$ & $1(2)$ & $0(0)$ & $165(90)$ & $13(7)$ & $3(2)$ & $2(1)$ & $1.1(0.4)$ & $1.0(0.3)$ & $1.1(0.5)$ & 0.62 \\
\hline $\begin{array}{l}\text { Believe in the power of } \\
\text { witchcraft, voodoo or the } \\
\text { occult }\end{array}$ & $21(59)$ & $6(17)$ & $4(11)$ & $5(14)$ & $41(66)$ & $9(15)$ & $5(8)$ & $7(11)$ & $123(67)$ & $41(22)$ & $8(4)$ & $12(7)$ & $1.9(1.1)$ & $1.6(1.0)$ & $1.5(0.9)$ & 0.05 \\
\hline $\begin{array}{l}\text { People look at you oddly because } \\
\text { of appearance }\end{array}$ & $17(49)$ & $13(37)$ & $5(14)$ & $0(0)$ & $21(33)$ & $29(46)$ & $7(11)$ & $6(10)$ & $55(30)$ & $75(41)$ & $39(21)$ & $15(8)$ & $1.8(0.8)$ & $1.9(0.1)$ & $2.1(0.9)$ & 0.10 \\
\hline $\begin{array}{l}\text { Thoughts in your head are being } \\
\text { taken away }\end{array}$ & $30(83)$ & $6(17)$ & $0(0)$ & $0(0)$ & $55(87)$ & $6(10)$ & $2(3)$ & $0(0)$ & $166(90)$ & $15(8)$ & $2(1)$ & $2(1)$ & $1.2(0.4)$ & $1.1(0.4)$ & $1.1(0.5)$ & 0.82 \\
\hline $\begin{array}{l}\text { Thoughts in your head are not } \\
\text { your own }\end{array}$ & $26(72)$ & $7(19)$ & $3(8)$ & $0(0)$ & $40(64)$ & $17(27)$ & $4(6)$ & $2(3)$ & $135(73)$ & $39(21)$ & $11(6)$ & $1(1)$ & $1.4(0.7)$ & $1.5(0.7)$ & $1.3(0.6)$ & 0.41 \\
\hline $\begin{array}{l}\text { So vivid thoughts that you were } \\
\text { worried other people would } \\
\text { hear them }\end{array}$ & $25(69)$ & $10(28)$ & $0(2)$ & $1(3)$ & $46(74)$ & $10(16)$ & $5(8)$ & $1(2)$ & $151(82)$ & $25(14)$ & $6(3)$ & $3(2)$ & $1.4(0.7)$ & $1.3(0.7)$ & $1.2(0.6)$ & 0.29 \\
\hline $\begin{array}{l}\text { Your own thoughts have been } \\
\text { echoed back to you }\end{array}$ & $24(69)$ & $8(23)$ & $2(6)$ & $1(3)$ & $44(71)$ & $10(16)$ & $5(7)$ & $4(7)$ & $136(74)$ & $36(20)$ & $12(7)$ & $1(0.5)$ & $1.5(0.8)$ & $1.4(0.8)$ & $1.3(0.6)$ & 0.25 \\
\hline $\begin{array}{l}\text { You are under the control of } \\
\text { some force or power }\end{array}$ & $22(61)$ & $7(19)$ & $5(14)$ & $2(6)$ & $44(70)$ & $14(22)$ & $3(5)$ & $2(3)$ & $138(74)$ & $41(22)$ & $3(2)$ & $4(2)$ & $1.7(1.0)$ & $1.3(0.6)$ & $1.3(0.6)$ & $0.00^{\mathrm{b}}$ \\
\hline Hear voices when you are alone & $34(77)$ & $8(18)$ & $2(5)$ & $0(0)$ & $40(74)$ & $11(20)$ & $2(4)$ & $1(2)$ & $143(77)$ & $38(209$ & $2(1)$ & $3(2)$ & $1.3(0.5)$ & $1.3(0.6)$ & $1.2(0.6)$ & 0.79 \\
\hline Hear voices talking to each other & $32(89)$ & $4(11)$ & $0(0)$ & $0(0)$ & $58(92)$ & $5(8)$ & $0(0)$ & $0(0)$ & $170(92)$ & $10(5)$ & $1(0.5)$ & $3(1)$ & $1.1(0.3)$ & $1.1(0.3)$ & $1.1(0.5)$ & 0.90 \\
\hline $\begin{array}{l}\text { Double had taken the place of a } \\
\text { family member, friend or } \\
\text { acquaintance }\end{array}$ & $35(97)$ & $1(3)$ & $0(0)$ & $0(0)$ & $59(95)$ & $3(5)$ & $0(0)$ & $0(0)$ & $179(97)$ & $3(2)$ & $0(0)$ & $3(2)$ & $1.1(0.3)$ & $1.0(0.1)$ & $1.0(0.4)$ & 0.76 \\
\hline $\begin{array}{l}\text { See objects, people or animals } \\
\text { that other people cannot see }\end{array}$ & $35(97)$ & $1(3)$ & $0(0)$ & $0(0)$ & $51(81)$ & $11(18)$ & $0(0)$ & $1(2)$ & $167(90)$ & $16(9)$ & $2(1)$ & $1(0.5)$ & $1.1(0.3)$ & $1.2(0.5)$ & $1.1(0.4)$ & 0.62 \\
\hline
\end{tabular}

a $P$ by ANOVA.

${ }^{\mathrm{b}}$ The mean of item scores is higher in patients with BD-1 $(n=36)$ than BD-2 $(n=63)$ or UD $(n=188)(P<0.05$ in post hoc by Turkey's HSD). 
Table 4

Correlations (Spearman's) between total scores of self-reported scales in patients with mood disorders $(n=282)$.

\begin{tabular}{lllllll}
\hline Scale & CAPE-42 & SPQ-B & BDI & MDQ & MSI & OASIS \\
\hline $\mathrm{SPQ}^{\mathrm{a}}$ & $0.68^{*}$ & 1.0 & $0.5^{*}$ & $0.32^{*}$ & $0.62^{*}$ & $0.53^{*}$ \\
$\mathrm{BDI}^{\mathrm{a}}$ & $0.67^{*}$ & $0.50^{*}$ & 1.0 & 0.07 & $0.40^{*}$ & $0.70^{*}$ \\
$\mathrm{MDQ}^{\mathrm{a}}$ & $0.33^{*}$ & $0.32^{*}$ & 0.07 & 1.0 & $0.41^{*}$ & $0.20^{*}$ \\
$\mathrm{MSI}^{\mathrm{a}}$ & $0.61^{*}$ & $0.62^{*}$ & $0.40^{*}$ & $0.41^{*}$ & $1.0^{*}$ & $0.45^{*}$ \\
$\mathrm{OASIS}^{\mathrm{a}}$ & $0.64^{*}$ & $0.53^{*}$ & $0.70^{*}$ & $0.20^{*}$ & $0.46^{*}$ & 1.0 \\
$\mathrm{CAPE}^{*} 42 \mathrm{fps}^{\mathrm{a}}$ & $0.7^{*}$ & $0.63^{*}$ & $0.39^{*}$ & $0.37^{*}$ & $0.56^{*}$ & $0.44^{*}$ \\
$\mathrm{CAPE}^{*} 42 \mathrm{nps}^{\mathrm{a}}$ & $0.8^{*}$ & $0.58^{*}$ & $0.67^{*}$ & 0.1 & $0.35^{*}$ & $0.63^{*}$ \\
CAPE-42 dps $^{\mathrm{a}}$ & $0.8^{*}$ & $0.56^{*}$ & $0.80^{*}$ & 0.1 & $0.49^{*}$ & $0.60^{*}$ \\
Paranoia & & $0.5^{*}$ & $0.3^{*}$ & $0.6^{*}$ & $0.5^{*}$ & $0.6^{*}$ \\
Grandiosity $^{\mathrm{b}}$ & & $0.2^{*}$ & 0 & $0.4^{*}$ & $0.2^{*}$ & 0.1 \\
Magical thinking & & $0.3^{*}$ & 0 & $0.1^{*}$ & $0.2^{*}$ & 0 \\
Delusions & & $0.4^{*}$ & $0.3^{*}$ & $0.3^{*}$ & $0.4^{*}$ & $0.3^{*}$ \\
Hallucinations & & $0.4^{*}$ & $0.3^{*}$ & $0.2^{*}$ & $0.4^{*}$ & $0.2^{*}$ \\
\hline
\end{tabular}

SPQ-B: Schizotypal Personality Questionnaire-Brief; BDI: Beck Depression Inventory; MDQ: Mood Disorder Questionnaire; MSI: McLean Screening Instrument; OASIS: Overall Anxiety Severity and Impairment Scale; CAPE-42: Community Assessment of Psychic Experiences; CAPE-42 fps; the "frequency of positive symptoms" of CAPE-42; CAPE-42 nps: the "frequency of negative symptoms" of CAPE-42; CAPE-42 dps: the "frequency of depressive symptoms" of CAPE-42.

$P<0.001$.

a $\alpha_{\text {alerted }}=0.008$

b $\alpha_{\text {alerted }}=0.01$.

Table 5

Hierarchical multiple regression predicting the frequency of positive symptoms from age, sex, BDI, OASIS; MDQ and MSI $(n=282)$.

\begin{tabular}{|c|c|c|c|c|}
\hline & \multicolumn{2}{|l|}{ Model 1} & \multicolumn{2}{|l|}{ Model 2} \\
\hline & B & Beeta & B & Beeta \\
\hline Constant & 35.6 & & 22.0 & \\
\hline Age & $-0.137^{*}$ & $0.250^{*}$ & $-0.062^{*}$ & 0.113 \\
\hline Sex & -0.724 & -0.047 & -0.781 & -0.050 \\
\hline BDI & & & 0.06 & 0.102 \\
\hline OASIS & & & $0.245^{*}$ & 0.161 \\
\hline MDQ & & & $0.223^{*}$ & 0.139 \\
\hline MSI & & & $0.852^{*}$ & 0.326 \\
\hline $\mathrm{R} 2$ & 0.062 & & 0.352 & \\
\hline $\mathrm{F}$ & $8.0^{* * *}$ & & $21.7^{* *}$ & \\
\hline$\Delta \mathrm{R} 2$ & 0.062 & & 0.290 & \\
\hline$\Delta \mathrm{F}$ & $8.0^{* * *}$ & & $26.9^{* *}$ & \\
\hline
\end{tabular}

Model 1 (sex, age); Model 2 (age, sex, BDI, OASIS, MDQ, MSI); MSI: McLean Screening Instrument; BDI: Beck Depression Inventory; OASIS: Overall Anxiety Severity and Impairment Scale; MDQ: Mood Disorder Questionnaire. ${ }^{*} P<0.05$.

$P<0.005$.

disorder patients. A strength of our study was the relatively large number of mood disorder patients, recruited by using stratified sampling, from the specialized psychiatric care services of the capital area of Helsinki. Moreover, extensive data of self-reported symptoms were collected. However, some limitations are also present. First, the response rate was only $43 \%$, perhaps because the survey was conducted in busy routine service units. Nevertheless, the analysis of representativeness indicated no significant differences in terms of age or sex between our cohort and the whole population of patients treated in the years 2011 and 2012. Moreover, the sample did not differ in terms of the demographics from the screening-based, representative Vantaa Depression Study (UD) and Jorvi Bipolar Study (BD) cohorts from the same area $[27,67]$. Second, the clinical diagnoses were not verified with structured clinical diagnostic interview instruments. However, all patients had been diagnosed with mood disorders in psychiatric services specialized in mood disorders. All diagnostic information was re-evaluated by the authors. Furthermore, the focus of this study was on self-reported symptoms, not on the diagnosis per se. The self-report could be affected by impairments in patients' self-reflection and social cognition. We acknowledge that use of observer-rated scales would have strengthened the study. First, there are some differences regarding the time span of reporting the symptoms in the instruments (for instance, lifetime psychotic symptoms in CAPE-42, but current symptoms of depression in BDI), which may be confusing for patients with serious pathology. Overall, whether the PEs symptoms described in the CAPE and those in the other scales are concurrent or temporally distinct remains unknown. It is also important to note, that the CAPE measures frequency of occurrence of PEs over the lifetime, not e.g. severity of PEs symptoms during a distinct illness episode. Fourth, the responses were not controlled by scales of desirability or infrequency.

The high co-occurrence and noticeable phenomenological overlap of psychotic and mood disorders on the clinical and subclinical levels have been widely discussed [18,26,38,63]. In line with previous research, we noted that the self-reported PEs are prevalent among patients with mood disorders. Interestingly, there were no differences between positive symptom frequency scores of mood disorder patients with or without a history of psychotic symptoms. Moreover, a significant proportion of patients with mood disorders tended to report PEs "sometimes" or "often". For example, although only $8 \%$ of patients had a psychotic depression as a lifetime diagnosis, 30\% of patients responded "often" or "always" to the item "Do you ever feel as if people seem to drop hints about you or say things with a double meaning?" and 29\% to the item "Do you ever feel that people look at you oddly because of your appearance?". Thus, self-reported PEs in patients with mood disorders appear to be notably more prevalent than clinical psychotic symptoms. However, it is not possible to distinguish PEs and frank psychotic symptoms using a self-report questionnaire, and therefore some of these patients may actually have had a psychotic episode.

The item-by-item analysis indicated that some items of BDI correlated with items of CAPE-42 while others did not. For instance, such self-reported depression symptoms like "guilty feelings", "punishment feelings", "self-criticalness", and "worthlessness" correlated moderately with such self-reported PEs as "hints and double meanings", "odd looks", "being persecuted and some others". This is in line with previous studies indicating that subjects who reported feeling of worthlessness or guilt were more likely to have psychotic symptoms [35,64]. Moreover, such selfreported PEs like "being special" and "destined to be important" correlated consistently with the majority of self-reported symptoms of mania and hypomania. Thus, items reflecting essential cognitive distortions associated with depression, mania or hypomania appear to correlate coherently with mood-congruent self-reported PE. Consequently, individuals scoring higher on items reflecting mania-, hypomania- or depression-related cognitive biases tend to more often report PEs.

Psychosis-like symptoms are also one of the core characteristics of BPD and SPD [29]. We have previously demonstrated that selfreported features of SPD and BPD are prevalent and intercorrelated in patients with mood disorders [65]. In particular, self-reported dissociative symptoms, distrustfulness and identity disturbance of BPD correlated moderately with self-reported schizotypal symptoms. Convergently, mood disorder patients reporting BPD features "dissociative symptoms", "distrustfulness" and "identity disturbance" appear to report PEs more often than mood disorder patients without BPD features. Furthermore, the majority of items of SPD correlated moderately or strongly with self-reported PE. This is probably due to similarities between contents of some items of "positive symptoms" scale of CAPE-42 and "cognitive-perceptual" dimension of SPQ-B. On the other hand, a substantial phenomenological overlap between symptoms of SPD and schizophrenia may also underlie high correlations between CAPE-42 and SPQ-B items. Thus, mood disorder patients reporting features of SPD may also more often report PEs. 
We demonstrated that symptoms of anxiety, mania or hypomania, BPD and SPD independently predict frequency of PEs. In other words, the more complicated the phenomenology of mood disorders, the more frequent the PEs. This finding supports previous studies demonstrating an association of psychotic symptoms with more severe mental illness [66]. In contrast, after adjusting for the other factors, current depressive symptoms did not predict PEs. The DSM-5 does not necessitate high severity for diagnosing a major depressive episode with psychotic features [29]. Furthermore, some studies have proposed that psychotic symptoms in UD reflect individual variation in susceptibility to psychosis rather than severity of depressive symptoms [36]. However, it is important to note that our patients were recruited from psychiatric care units specialized in treatment of mood disorders and therefore tended to have severe depression, which could affect the generalizability of findings.

To evaluate findings based on self-report it is important to consider the form and content of items. The CAPE does not include definitions regarding duration and intensity for the PEs. Consequently, individuals with mood disorders, who in the past had experienced psychotic symptoms during an episode of psychotic depression or psychotic mania, may answer "sometimes" or "often" on the CAPE-42 questions. Our findings are therefore more a reflection of factors correlating with trait-like tendencies to psychotic-like symptoms, rather than presence of psychotic symptoms during a mood episode.

Overall, there is a high prevalence of self-reported PEs in mood disorder patients. Moreover, even patients without clinical diagnoses of psychotic (unipolar or bipolar) depression or mania tend to report PEs. Self-reported features of BPD and SPD, symptoms of anxiety and cognitive distortions related to depression and mania or hypomania appear to aggravate reporting of PEs in patients with mood disorders. An accurate comprehensive clinical diagnostic interview is needed to distinguish clinically relevant psychotic symptoms from self-reported PEs in patients with mood disorders.

\section{Conclusions}

Self-reported PEs are common in patients with mood disorders. Multiple factors appear to predict reporting of them: self-reported cognitive-perceptual distortions of schizotypal personality disorder; dissociative symptoms, distrustfulness and identity disturbance of borderline personality disorder; and cognitive biases of depression and mania or hypomania. Comprehensive clinical interviews are necessary to distinguish PEs associated with these factors from frank psychotic symptoms. Careful assessment of features of personality disorders is important in patients with mood disorders who have PEs.

\section{Disclosure of interest}

The authors declare that they have no competing interest.

\section{Appendix A. Supplementary data}

Supplementary data associated with this article can be found, in the online version, at http://dx.doi.org/10.1016/j.eurpsy.2016.07. 005 .

\section{References}

[1] Kelleher I, Keeley H, Corcoran P, Lynch F, Fitzpatrick C, Devlin N, et al. Clinicopathological significance of psychotic experiences in non-psychotic young people: evidence from four population-based studies. Br J Psychiatry 2012:201(1):26-32

[2] Lee KW, Chan KW, Chang WC, Lee EH, Hui CL, Chen EY. A systematic review on definitions and assessments of psychotic-like experiences. Early Interv Psychiatry 2016;10(1):3-16.

[3] Linscott RJ, van Os J. Systematic reviews of categorical versus continuum models in psychosis: evidence for discontinuous subpopulations underlying a psychometric continuum. Implications for DSM-V, DSM-VI, and DSM-VII. Annu Rev Clin Psychol 2010;6:391-419.

[4] McGrath JJ, Saha S, Al-Hamzawi A, Alonso J, Bromet EJ, Bruffaerts R, et al. Psychotic experiences in the general population: a cross-national analysis based on 31,261 respondents from 18 countries. JAMA Psychiatry 2015;72(7):697-705.

[5] Verdoux H, van Os J. Psychotic symptoms in non-clinical populations and the continuum of psychosis. Schizophr Res 2002;54(1-2):59-65.

[6] Rossler W, Riecher-Rossler A, Angst J, Murray R, Gamma A, Eich D, et al. Psychotic experiences in the general population: A twenty-year prospective community study. Schizophr Res 2007;92(1-3):1-14.

[7] DeVylder JE, Burnette D, Yang LH. Co-occurrence of psychotic experiences and common mental health conditions across four racially and ethnically diverse population samples. Psychol Med 2014;44(16):3503-13.

[8] Saha S, Scott J, Varghese D, McGrath J. Anxiety and depressive disorders are associated with delusional-like experiences: A replication study based on a national survey of mental health and wellbeing. BMJ Open 2012;2(3). http:// dx.doi.org/10.1136/bmjopen.2012-001001.

[9] Hanssen M, Peeters F, Krabbendam L, Radstake S, Verdoux H, van Os J. How psychotic are individuals with non-psychotic disorders? Soc Psychiatry Psychiatr Epidemiol 2003;38(3):149-54.

[10] Fusar-Poli P, Nelson B, Valmaggia L, Yung AR, McGuire PK. Comorbid depressive and anxiety disorders in 509 individuals with an at-risk mental state: Impact on psychopathology and transition to psychosis. Schizophr Bull 2014;40(1):120-31

[11] Wigman JT, van Nierop M, Vollebergh WA, Lieb R, Beesdo-Baum K, Wittchen $\mathrm{HU}$, et al. Evidence that psychotic symptoms are prevalent in disorders of anxiety and depression, impacting on illness onset, risk, and severity-implications for diagnosis and ultra-high risk research. Schizophr Bull 2012;38(2):247-57.

[12] van Nierop M, van Os J, Gunther N, Myin-Germeys I, de Graaf R, ten Have M, et al. Phenotypically continuous with clinical psychosis, discontinuous in need for care: evidence for an extended psychosis phenotype. Schizophr Bull 2012:38(2):231-8.

[13] Gift TE, Strauss JS, Harder DW. The severity of psychiatric disorder. Psychiatry Res 1980;3(1):31-40

[14] Maj M, Pirozzi R, Di Caprio EL. Major depression with mood-congruent psychotic features: a distinct diagnostic entity or a more severe subtype of depression? Acta Psychiatr Scand 1990;82(6):439-44

[15] Kelleher I, Wigman JTW, Harley M, O'Hanlon E, Coughlan H, Rawdon C, et al Psychotic experiences in the population: association with functioning and mental distress. Schizophr Res 2015;165(1):9-14.

[16] Collip D, Wigman JT, Myin-Germeys I, Jacobs N, Derom C, Thiery E, et al. From epidemiology to daily life: linking daily life stress reactivity to persistence of psychotic experiences in a longitudinal general population study. PLoS One 2013;8(4):e62688.

[17] DeVylder JE, Lukens EP, Link BG, Lieberman JA. Suicidal ideation and suicide attempts among adults with psychotic experiences: data from the collaborative psychiatric epidemiology surveys. JAMA Psychiatry; 2015;72(3):219-25.

[18] Saha S, Scott JG, Johnston AK, Slade TN, Varghese D, Carter GL, et al. The association between delusional-like experiences and suicidal thoughts and behaviour. Schizophr Res 2011;132(2-3):197-202.

[19] Preti A, Bonventre E, Ledda V, Petretto DR, Masala C. Hallucinatory experiences, delusional thought proneness, and psychological distress in a nonclinical population. J Nerv Ment Dis 2007;195(6):484-91.

[20] Schultze-Lutter F, Renner F, Paruch J, Julkowski D, Klosterkotter J, Ruhrmann S. Self-reported psychotic-like experiences are a poor estimate of clinician-rated attenuated and frank delusions and hallucinations. Psychopathology 2014;47(3):194-201.

[21] Cardno AG, Owen MJ. Genetic relationships between schizophrenia, bipolar disorder, and schizoaffective disorder. Schizophr Bull 2014:40(3):504-15.

[22] Domschke K. Clinical and molecular genetics of psychotic depression. Schizophr Bull 2013;39(4):766-75.

[23] Busatto GF. Structural and functional neuroimaging studies in major depressive disorder with psychotic features: a critical review. Schizophr Bull 2013;39(4):776-86

[24] Frangou S. A systems neuroscience perspective of schizophrenia and bipolar disorder. Schizophr Bull 2014;40(3):523-31.

[25] Weiser M, van Os J, Davidson M. Time for a shift in focus in schizophrenia: from narrow phenotypes to broad endophenotypes. Br J Psychiatry 2005;187:203-5.

[26] Klaassen RM, Heins M, Luteijn LB, van der Gaag M, van Beveren NJ, Genetic Risk and Outcome of Psychosis (GROUP) investigators. Depressive symptoms are associated with (sub)clinical psychotic symptoms in patients with non-affective psychotic disorder, siblings and healthy controls. Psychol Med 2013;43(4):747-56

[27] Mantere O, Suominen K, Leppamaki S, Valtonen H, Arvilommi P, Isometsa E The clinical characteristics of DSM-IV bipolar I and II disorders: baseline findings from the jorvi bipolar study (JoBS). Bipolar Disord 2004;6(5): 395-405. 
[28] World Health Organization. International classification of disease, 10th ed., Geneva: WHO; 1992.

[29] American Psychiatric Association. The diagnostic and statistical manual of mental disorders, 5th ed., 2013.

[30] Parker G. Classifying depression: should paradigms lost be regained? Am J Psychiatry 2000;157(8):1195-203.

[31] Paykel ES. Basic concepts of depression. Dialogues Clin Neurosci 2008;10(3):279-89.

[32] Finlay-Jones R, Parker G. A consensus conference on psychotic depression. Aust N Z J Psychiatry 1993;27(4):581-9.

[33] Johnson J, Horwath E, Weissman MM. The validity of major depression with psychotic features based on a community study. Arch Gen Psychiatry 1991;48(12):1075-81.

[34] Lenzi A, Rinaldi A, Bianco I, Balestri C, Marazziti D. Psychotic symptoms in mood disorders: evaluation of 159 inpatients. Eur Psychiatry 1996;11(8):396-9.

[35] Ohayon MM, Schatzberg AF. Prevalence of depressive episodes with psychotic features in the general population. Am J Psychiatry 2002;159(11):1855-61.

[36] Forty L, Jones L, Jones I, Cooper C, Russell E, Farmer A, et al. Is depression severity the sole cause of psychotic symptoms during an episode of unipolar major depression? A study both between and within subjects. J Affective Disord 2009;114(1-3):103-9.

[37] Schatzberg AF, Rothschild AJ. Psychotic (delusional) major depression: should it be included as a distinct syndrome in DSM-IV? Am J Psychiatry 1992;149(6):733-45.

[38] Wigman JT, van Os J, Abidi L, Huibers MJ, Roelofs J, Arntz A, et al. Subclinical psychotic experiences and bipolar spectrum features in depression: association with outcome of psychotherapy. Psychol Med 2014;44(2):325-36.

[39] Mulder RT. Depression and personality disorder. Curr Psychiatry Rep 2004;6(1):51-7.

[40] Fan AH, Hassell J. Bipolar disorder and comorbid personality psychopathology: a review of the literature. J Clin Psychiatry 2008;69(11):1794-803.

[41] Mantere O, Melartin TK, Suominen K, Rytsala HJ, Valtonen HM, Arvilommi P, et al. Differences in axis I and II comorbidity between bipolar I and II disorders and major depressive disorder. J Clin Psychiatry 2006;67(4):584-93.

[42] Zanarini MC, Laudate CS, Frankenburg FR, Reich DB, Fitzmaurice G. Predictors of self-mutilation in patients with borderline personality disorder: a 10-year follow-up study. J Psychiatr Res 2011;45(6):823-8.

[43] Kline E, Wilson C, Ereshefsky S, Nugent KL, Pitts S, Reeves G, et al. Schizotypy, psychotic-like experiences and distress: an interaction model. Psychiatry Res 2012;200(2-3):647-51.

[44] Kleindienst N, Limberger MF, Ebner-Priemer UW, Keibel-Mauchnik J, Dyer A, Berger $\mathrm{M}$, et al. Dissociation predicts poor response to dialectial behavioral therapy in female patients with borderline personality disorder. J Pers Disord 2011;25(4):432-47.

[45] Ryan J, Graham A, Nelson B, Yung A. Borderline personality pathology in young people at ultra high risk of developing a psychotic disorder. Early Interv Psychiatry 2015.

[46] Rosell DR, Futterman SE, McMaster A, Siever LJ. Schizotypal personality disorder: a current review. Curr Psychiatry Rep 2014;16(7):452. 014-0452-1.

[47] Farahani A Correll CU. Are antipsychotics or antidepressants needed for psychotic depression? A systematic review and meta-analysis of trials comparing antidepressant or antipsychotic monotherapy with combination treatment. J Clin Psychiatry 2012;73(4):486-96.

[48] Calabrese JR, Keck Jr PE, Macfadden W, Minkwitz M, Ketter TA, Weisler RH, et al. A randomized, double-blind, placebo-controlled trial of quetiapine in the treatment of bipolar I or II depression. Am J Psychiatry 2005;162(7):1351-60.
[49] Scherk H, Pajonk FG, Leucht S. Second-generation antipsychotic agents in the treatment of acute mania: a systematic review and meta-analysis of randomized controlled trials. Arch Gen Psychiatry 2007;64(4):442-55.

[50] Konings M, Bak M, Hanssen M, van Os J, Krabbendam L. Validity and reliability of the CAPE: a self-report instrument for the measurement of psychotic experiences in the general population. Acta Psychiatr Scand 2006;114(1): 55-61.

[51] Baryshnikov I, Aaltonen K, Koivisto M, Näätänen P, Karpov B, Melartin T, et al. Differences and overlap in self-reported symptoms of bipolar disorder and borderline personality disorder. Eur Psychiatry 2015;30(8):914-9.

[52] Aaltonen K, Naatanen P, Heikkinen M, Koivisto M, Baryshnikov I, Karpov B, et al. Differences and similarities of risk factors for suicidal ideation and attempts among patients with depressive or bipolar disorders. J Affect Disord 2016;193:318-30.

[53] Therman S, Suvisaari J, Hultman CM. Dimensions of psychotic experiences among women in the general population. Int J Methods Psychiatr Res 2014;23(1):62-8.

[54] Zanarini MC, Vujanovic AA, Parachini EA, Boulanger JL, Frankenburg FR, Hennen J. A screening measure for BPD: the McLean screening instrument for borderline personality disorder (MSI-BPD). J Pers Disord 2003;17(6): 568-73.

[55] Melartin T, Hakkinen M, Koivisto M, Suominen K, Isometsa ET. Screening of psychiatric outpatients for borderline personality disorder with the McLean screening instrument for borderline personality disorder (MSI-BPD). Nord J Psychiatry 2009;63(6):475-9.

[56] Beck AT, Ward CH, Mendelson M, Mock J, Erbaugh J. An inventory for measuring depression. Arch Gen Psychiatry 1961;4:561-71.

[57] Norman SB, Cissell SH, Means-Christensen AJ, Stein MB. Development and validation of an overall anxiety severity and impairment scale (OASIS). Depress Anxiety 2006;23(4):245-9.

[58] Raine A. The SPQ: a scale for the assessment of schizotypal personality based on DSM-III-R criteria. Schizophr Bull 1991;17(4):555-64.

[59] Hirschfeld RMA, Williams JBW, Spitzer RL, Calabrese JR, Flynn L, Keck PEJ, et al. Development and validation of a screening instrument for bipolar spectrum disorder: the mood disorder questionnaire. Am J Psychiatry 2000;157(11): 1873-5.

[60] Isometsa E, Suominen K, Mantere O, Valtonen H, Leppamaki S, Pippingskold M, et al. The mood disorder questionnaire improves recognition of bipolar disorder in psychiatric care. BMC Psychiatry 2003;3:8.

[61] Evans JSBT, Over DE. Rationality and reasoning. Hove, England: Psychology press; 1996.

[62] IBM Corp.. Released 2013. IBM SPSS statistics for windows, version 22.0. Armonk, NY: IBM corp; 2013.

[63] Barragan M, Laurens KR, Navarro JB, Obiols JE. Psychotic-like experiences and depressive symptoms in a community sample of adolescents. Eur Psychiatry 2011;26(6):396-401.

[64] Thakur M, Hays J, Krishnan KR. Clinical, demographic and social characteristics of psychotic depression. Psychiatry Res 1999;86(2):99-106.

[65] Baryshnikov I, Suvisaari J, Aaltonen K, Koivisto M, Näätänen P, Karpov B, et al. Self-reported symptoms of schizotypal and borderline personality disorder in patients with mood disorders. Eur Psychiatry 2016;33:37-44.

[66] Tsuang MT, Stone WS, Faraone SV. Toward reformulating the diagnosis of schizophrenia. Am J Psychiatry 2000;157(7):1041-50.

[67] Melartin TK, Rytsala HJ, Leskela US, Lestela-Mielonen PS, Sokero TP, Isometsa ET. Current comorbidity of psychiatric disorders among DSM-IV major depressive disorder patients in psychiatric care in the vantaa depression study. J Clin Psychiatry 2002;63(2):126-34. 